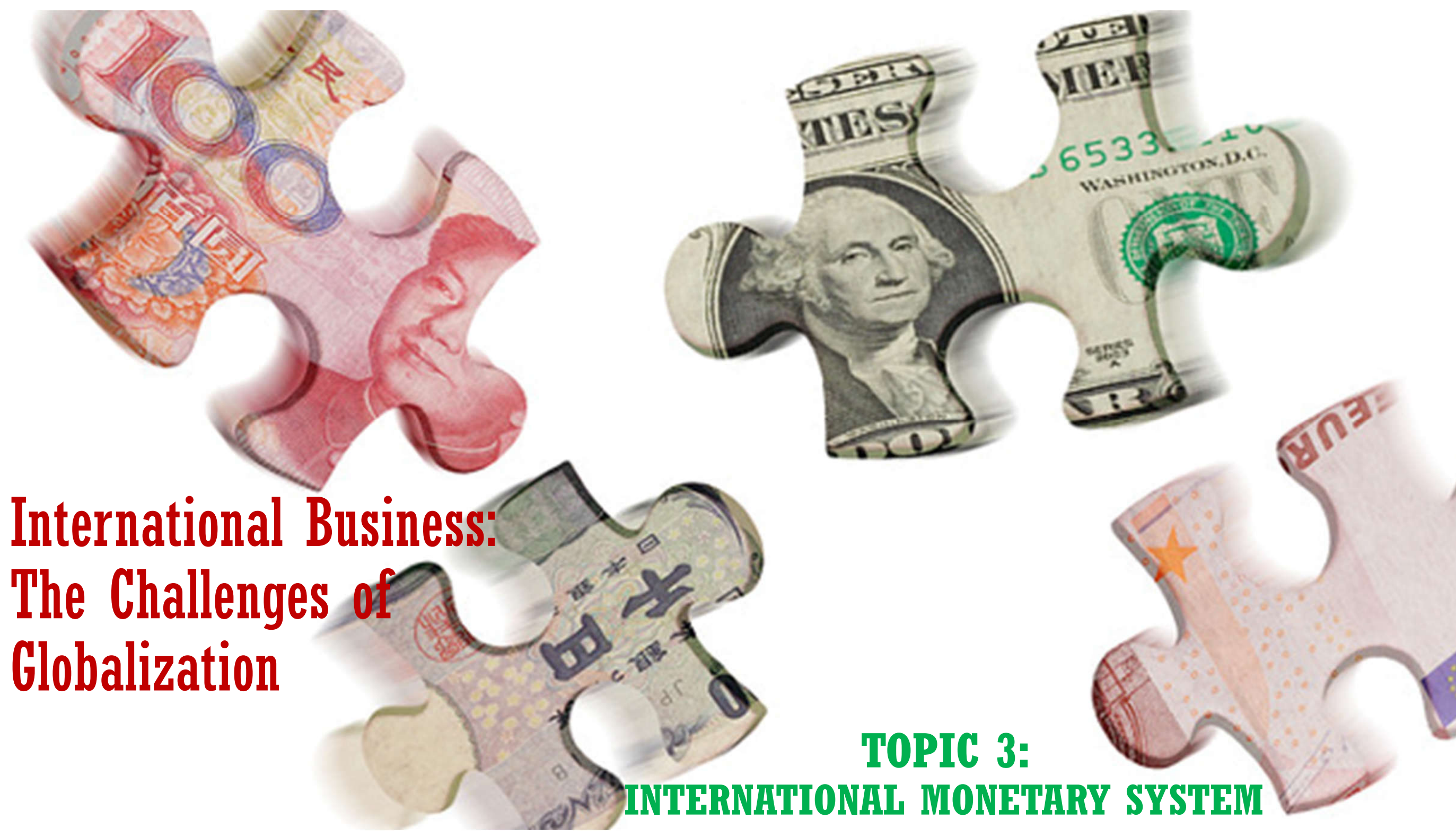


- The role of international monetary system is promoting in international trade and investment.

- Gold standards.

- The role of the IMF in post-world II. 


\section{WHAT IS MONEY?}
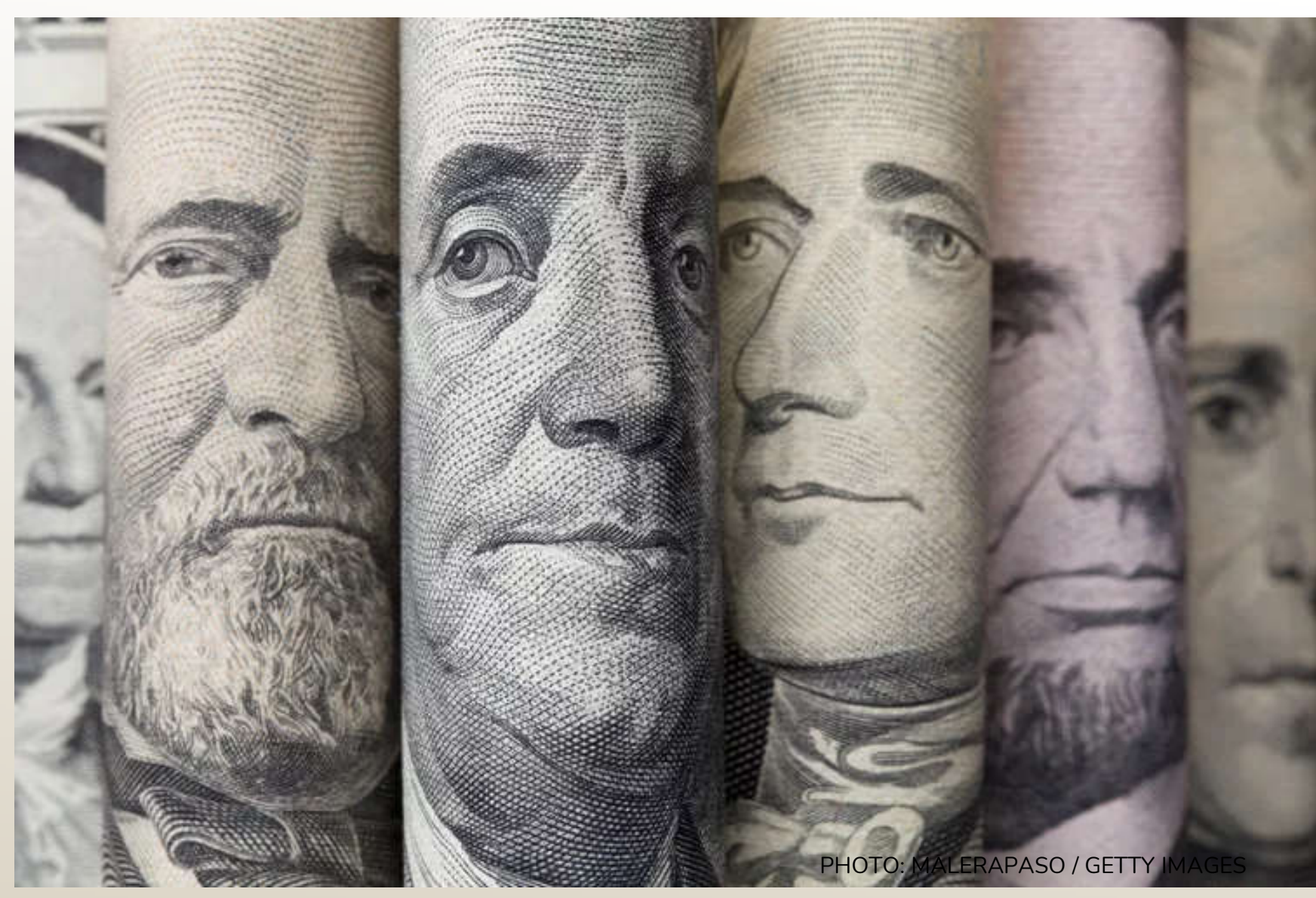


\section{WHAT IS \\ MONEY?}

- Money is anything that is a store of value and a medium of exchange.

- Money only has value because people agree to give it value.

- Money becomes valuable when everybody agrees to use it.

- Currency can be any sort of physical item, or electronic. 
- A medium of exchange - money used for

THREE FUNCTIONS OF MONEY

buying and selling goods and services.

- Unit of account - common standard for measuring relative worth of goods and services.

-Store of value - convenient way to store wealth 


\section{WHAT WAS THE GOLD STANDARD?}

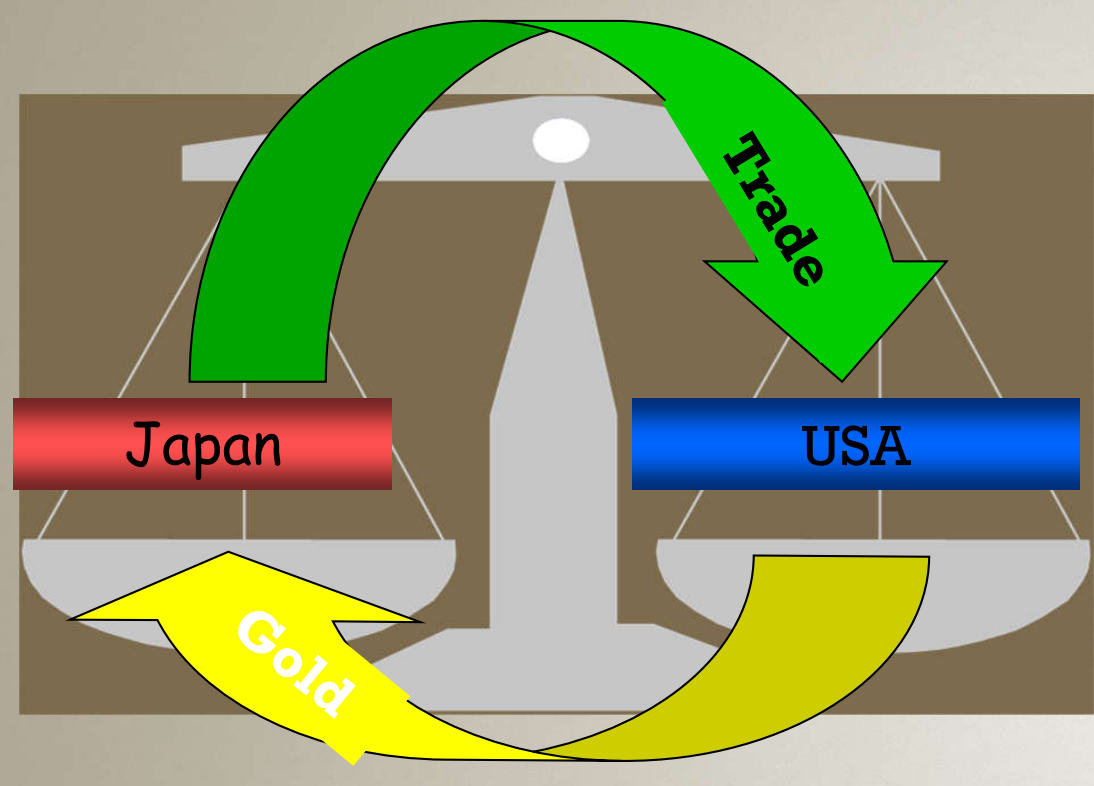

The gold standard is a monetary system where a currency is pegged to the price of a specific amount of gold. 


\section{WHAT WAS THE GOLD STANDARD?}

- The U.S. was only ever on a true gold standard from 1879 to 1933.

- The Bretton Woods Agreement attempted to create an international system with gold as a standard, but it failed.

- Any ties currency had to gold in the U.S. were severed in 1971 by

President Richard Nixon. 
WHAT WAS THE

BRETTON WOODS SYSTEM?

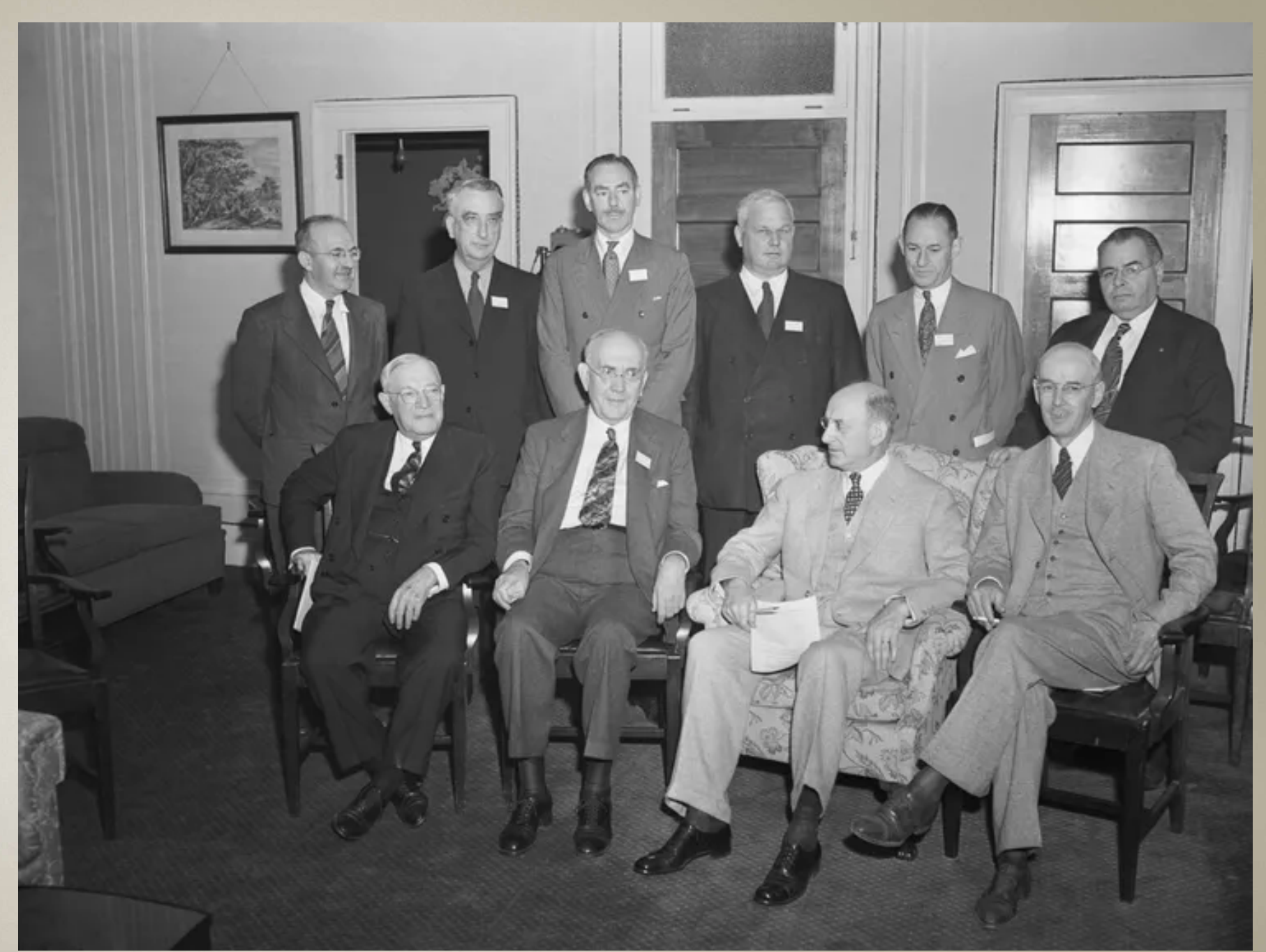




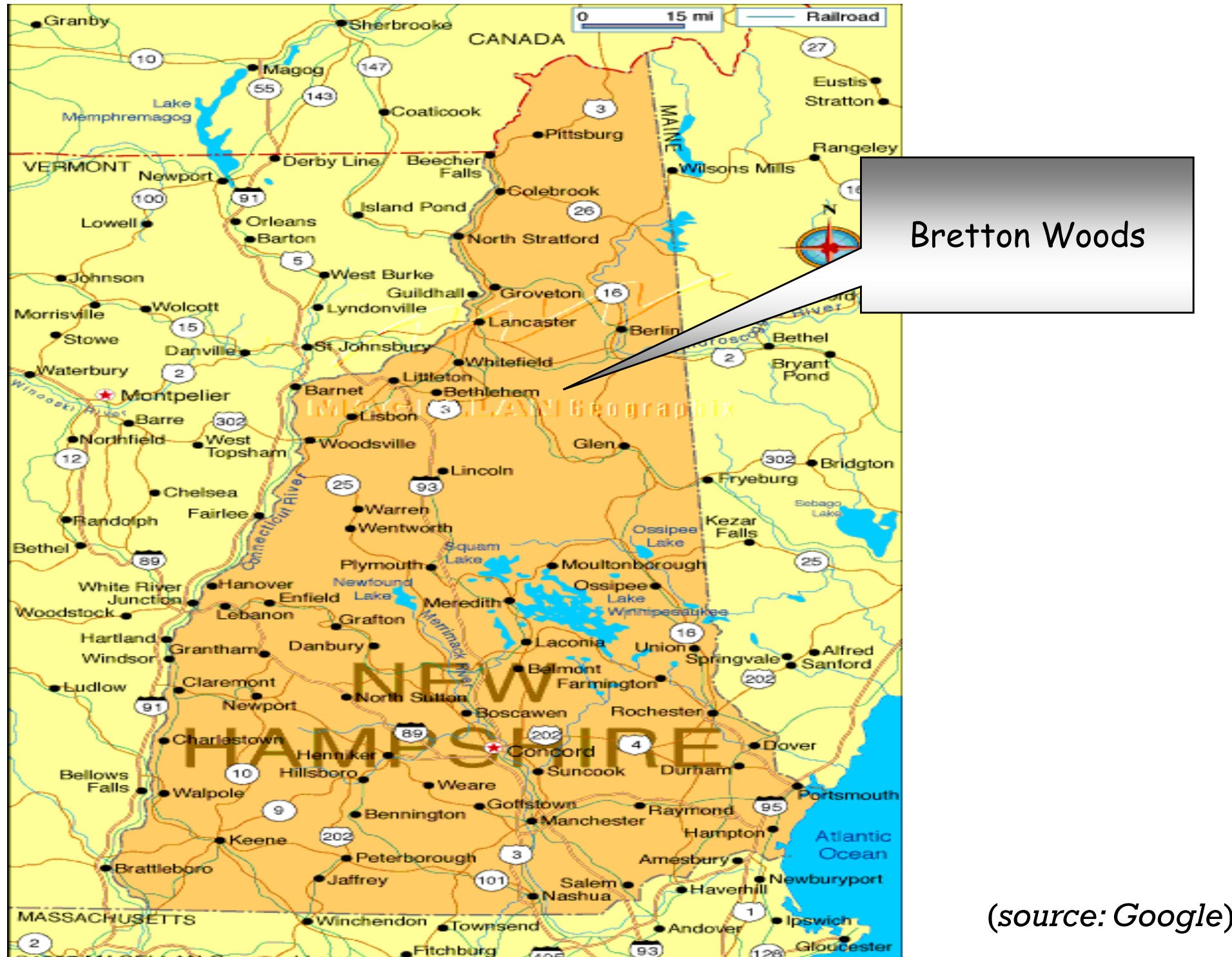


The Bretton Woods Agreement was created in a 1944

THE conference of all of the World War II Allied nations.

\section{BRETTON}

WOODS

AGREEMENT

\section{Under the agreement:}

$\checkmark$ The country's central banks promised to maintain fixed exchange rates between their currencies and the dollar. $\checkmark$ A country's currency value became too weak relative to the dollar, the bank would buy up its currency in foreign exchange markets. 


\section{THE \\ BRETTON WOODS AGREEMENT}

- The Bretton Woods agreement of 1944 established a new international monetary system.

- Replaced the gold standard with the U.S. dollar as the global currency.

- The U.S. became dominant in the world economy.

The agreement created the World Bank and the International Monetary Fund (IMF) 


\section{The US Dollar as the Global Currency}
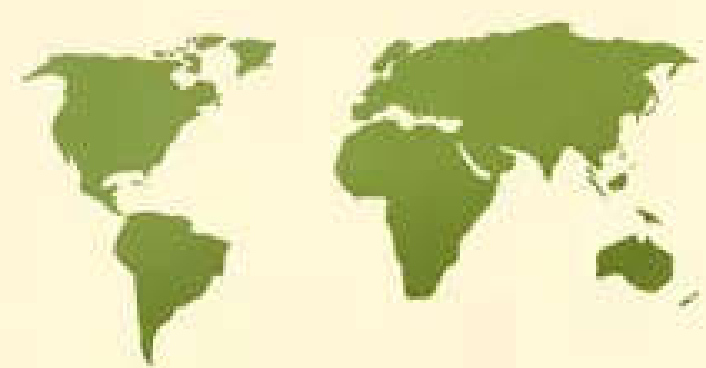

The 1944 Bretton Woods agreement allowed other countries to back their currencies with dollars rather than gold

\begin{tabular}{|c|c|c|c|c|}
\hline S & USD & & +2.74 & $\Lambda$ \\
\hline $\mathcal{C}$ & EUR & & +2.31 & $\Lambda$ \\
\hline $\mathcal{C}$ & GBP & & -0.41 & $\nabla$ \\
\hline $\boldsymbol{X}$ & JPY & - & +3.16 & $\Lambda$ \\
\hline AS & AUD & & +2.71 & $\Lambda$ \\
\hline
\end{tabular}

The dollar rules the foreign exchange market

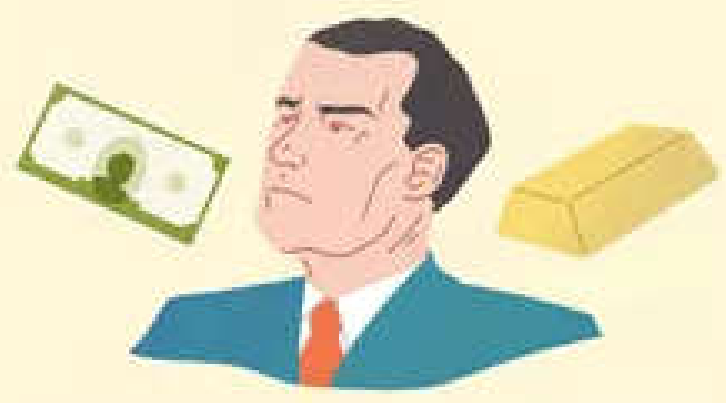

In the early 1970 s, former President Nixon separated the dollar from gold

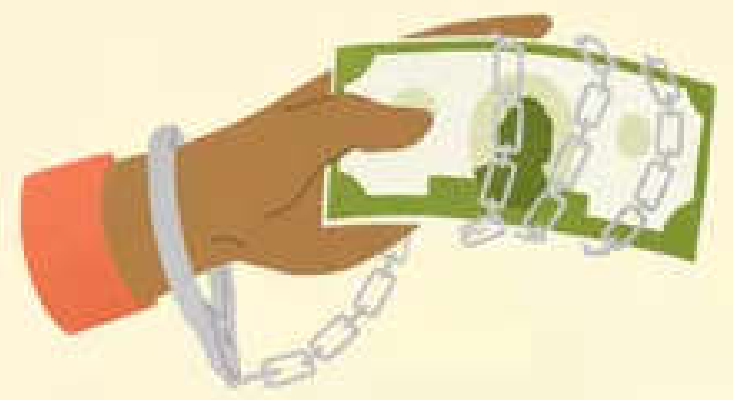

Nearly $40 \%$ of the world's debt is issued in dollars

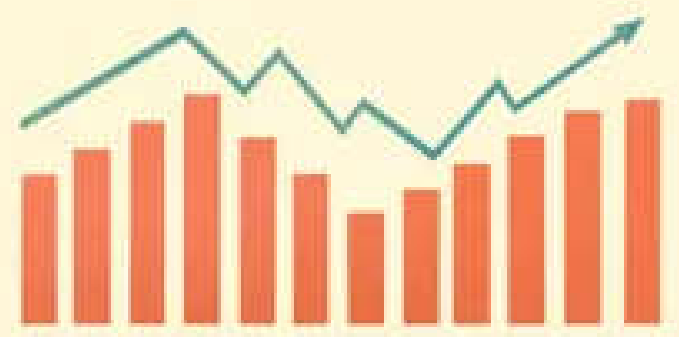

The relative strength of the U.S. economy supports the value of the dollar

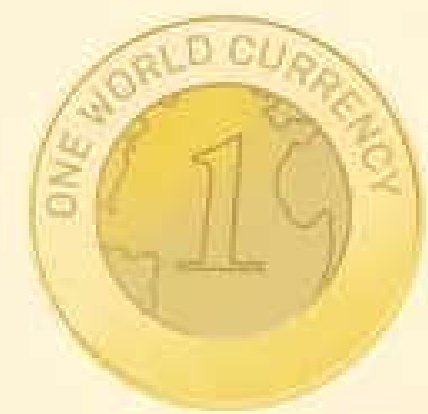

Countries like China and Russia are currently calling for a 


\section{ROLE OF THE IMF AND}

\section{WORLD BANK ON THE - Member countries needed IMF to}

\section{BRETTON WOODS AGREEMENT}

- Each member country of the BW system was then entitled to borrow what it needed, within the limits of its contributions. held by the IMF.

bail them out if their currency

values got too low.

- Member countries agreed to contribute to a fixed pool of national currencies and gold to be 


\section{THE BRETTON WOODS AGREEMENT REPLACING THE GOLD STANDARD}

- Before Bretton Woods, each country followed the gold standard by guaranteed that it would redeem its currency for its value in gold.

- After Bretton Woods, each member agreed to redeem its currency for U.S. dollars, not gold. 


\section{WHAT IS THE INTERNATIONAL MONETARY SYSTEM?}
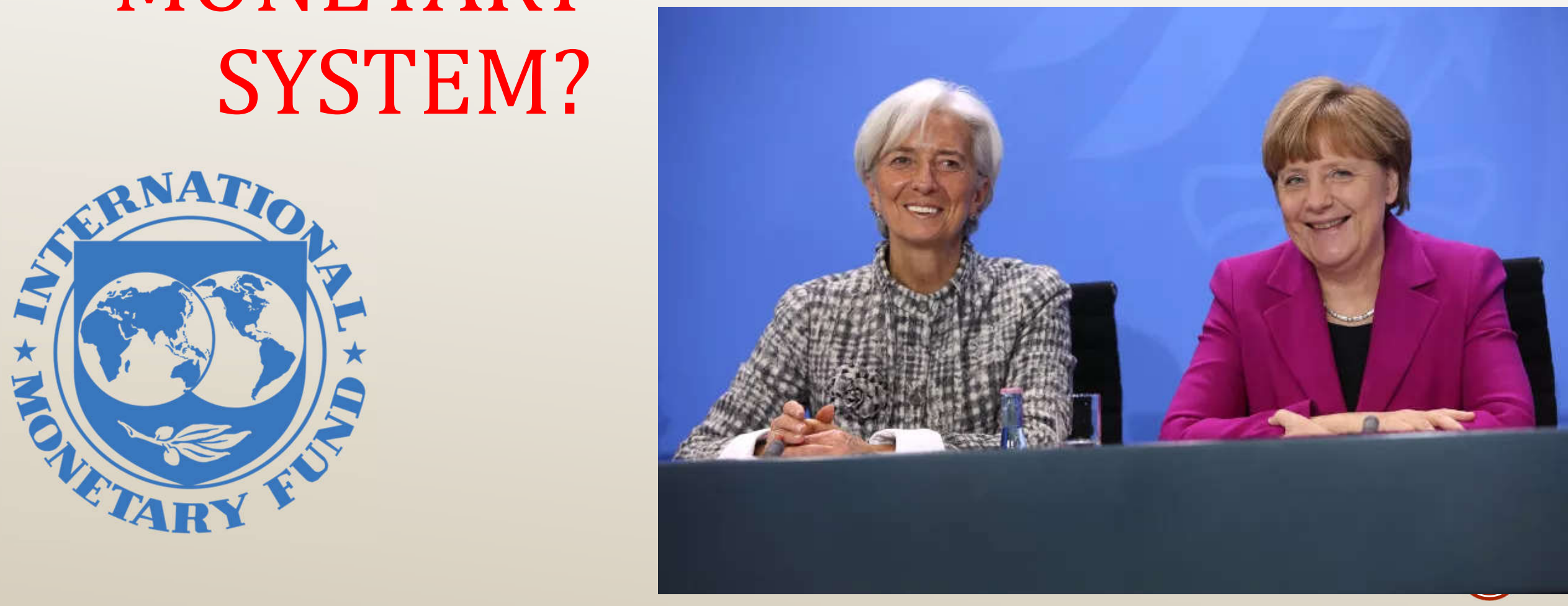


\section{WHAT IS THE \\ INTERNATIONAL \\ MONETARY \\ SYSTEM?}

- The IMF was created at the 1944 Bretton Woods conference.

- The IMF is a 189-member organization that works to stabilize the global economy. 


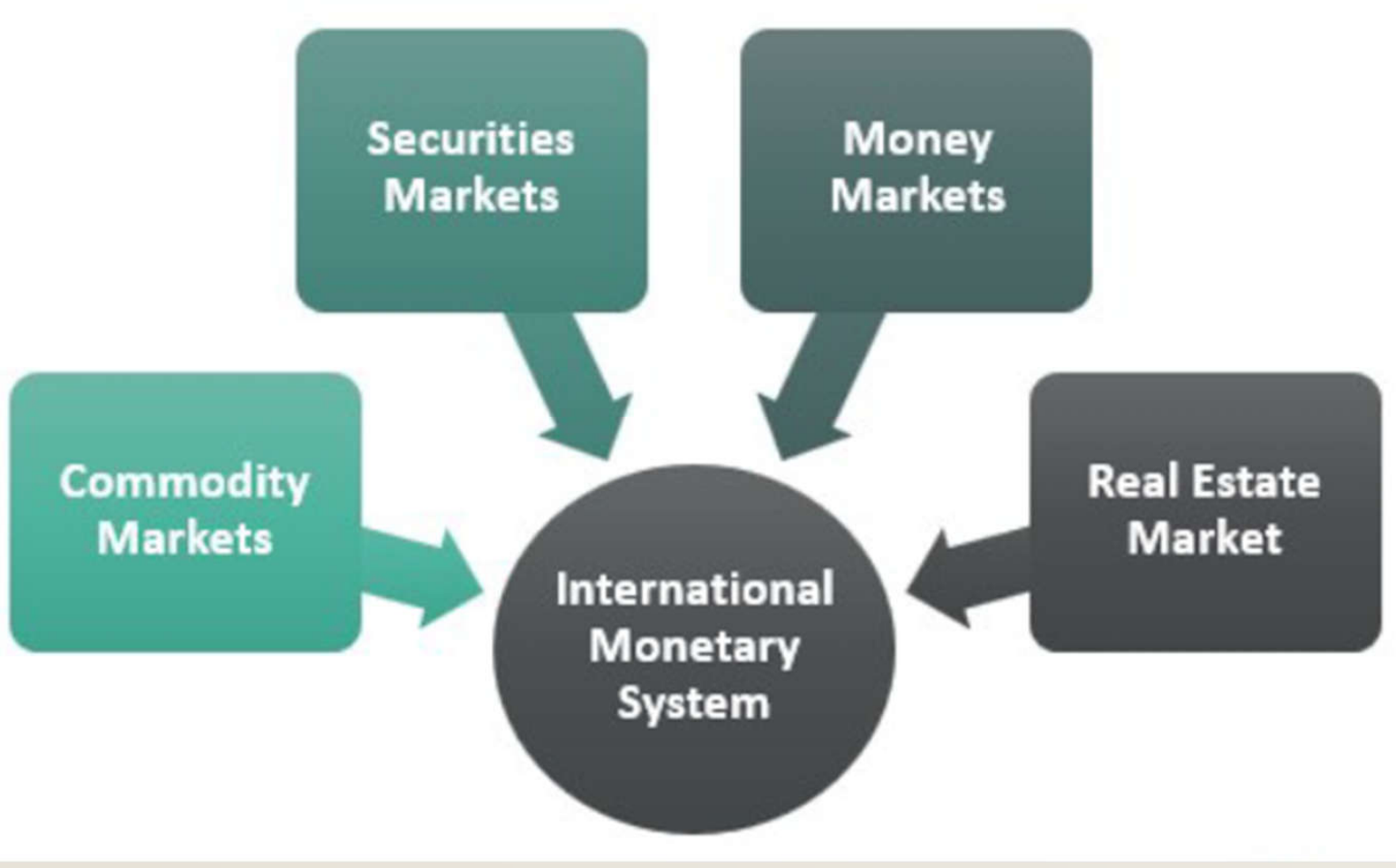

A set of conventions and rules that support cross-border investments, trades, and the reallocation of capital between different countries. 
- The IMF monitors and identifies risks among its member countries.

\section{THE IMF OBJECTIVES}

- The IMF advises members on how to improve their economies.

- The IMF provides technical assistance and short-term loans to prevent financial crises. 
- Facilitates the free flow of different currencies in the open market.

- Restrict intervention from government only in

FUNCTIONS OF IMF cases of currency stabilization.

- Facilitate global trade of goods, services, and money.

- Maintain a system that regulates the exchange rates through the forces of the market. 


\section{END OF TOPIC 3}

